\title{
Projecting the Potential Effect of Using Paliperidone Palmitate Once-Monthly and Once-Every-3-Months Long-Acting Injections Among Medicaid Beneficiaries with Schizophrenia
}

\author{
Anirban Basu, PhD; Carmela Benson, MS, MSHP; and Larry Alphs, MD, PhD
}

\begin{abstract}
BACKGROUND: Once-monthly and once-every-3-months long-acting injectable (LAI) formulations of paliperidone palmitate (PP1M and PP3M, respectively) are available for the treatment of patients with schizophrenia. However, information on the comparative effectiveness and costs of using these LAls versus oral antipsychotics (OAs) is not available. The population effectiveness of using these treatments is also not known.
\end{abstract}

OBJECTIVE: To project the effect of using PP1M and PP3M LAls on psychiatric (Psych) and all-cause (AC) hospitalization rates over 18 months in patients with schizophrenia receiving Medicaid and treated with 0 As.

METHODS: A decision model, informed by data from 3 randomized controlled trials (PRIDE [NCT01157351], 3001 [NCT00111189], and 3012 [NCT01529515]), was developed to compare 3 strategies: (a) initiating OA and switching only to $0 A$; (b) initiating with PP1M and continuing PP1M if the patient was stable at 6 months (or switching to $O A$ if unstable; $\mathrm{PP} 1 \mathrm{M} \rightarrow \mathrm{PP} 1 \mathrm{M}$ ); and (c) initiating with PP1M and switching to PP3M if the patient was stable at 6 months (or switching to $O A$ if unstable; $\mathrm{PP} 1 \mathrm{M} \rightarrow \mathrm{PP} 3 \mathrm{M})$. PRIDE data were used to inform the first 6-month outcomes; 3001 and 3012 data were used to inform outcomes in stable patients over the following 12 months. The primary outcome for this decision model study was Psych hospitalizations. AC hospitalizations and time to discontinuation were also assessed. Outcomes from each arm and time portions within an arm were reweighted to reflect the distribution of patient characteristics found in the real-world Medicaid sample with PRIDE trial inclusion/exclusion criteria applied. Several validation exercises were carried out to ensure that the reweighted results could reproduce observed outcomes in the Medicaid sample.

RESULTS: Our final target real-world sample size was $N=4,609$. We found that in the Medicaid sample, compared with initiating treatments with $0 A$, the PP1M $\rightarrow$ PP1M strategy was projected to produce a per patient decrease of $0.27(95 \% \mathrm{Cl}=-0.43-0.97)$ and $0.28(95 \% \mathrm{Cl}=-0.28-0.84)$ in Psych- and AC-related hospitalizations, respectively. Similarly, the PP1M $\rightarrow$ PP3M strategy was projected to produce a per patient decrease of $0.31(95 \% \mathrm{Cl}=$ -0.27-0.87) in both Psych- and AC-related hospitalizations over $0 \mathrm{~A}$.

Validation exercises ensured that the reweighting methodology used could replicate observed outcomes in the Medicaid sample. These incremental reductions in hospitalization rates are worth about \$3.4-\$3.8 billion over an 18-month period in patients with schizophrenia receiving Medicaid.

CONCLUSIONS: Our results suggest that using PP1M and PP3M treatment strategies for patients with schizophrenia receiving Medicaid could result in reduced hospitalizations. This finding, along with improvement to patients' health, should be considered when assessing the value of these LAls.

J Manag Care Spec Pharm. 2018;24(8):759-68

Copyright $\odot 2018$, Academy of Managed Care Pharmacy. All rights reserved.

\section{What is already known about this subject}

The long-acting injectable (LAI) antipsychotics paliperidone palmitate once-monthly (PP1M) and once-every-3-months (PP3M) formulations have shown efficacy in clinical trials of patients with schizophrenia; however, the population effectiveness of PP1M and PP3M is unknown.

Propensity-based methods can be used to project the real-world effect of a new therapy based on existing trial data, thereby providing valuable information to payers without conducting extensive and time-consuming research.

\section{What this study adds}

This is the first decision model to use PP1M and PP3M trial data to project the outcome of oral antipsychotic $(\mathrm{OA})$-treated patients if they switched to PP1M or PP1M $\rightarrow$ PP3M.

The projection was built on patient-level clinical trial data that were projected onto a Medicaid population

Our results show that over an 18-month period, switching from

OAs to PP1M or PP3M could produce substantial reductions in psychiatric- and all-cause-related hospitalizations

$\mathrm{P}$ oor continuity of treatment is an ongoing challenge for individuals with schizophrenia, leading to relapse of symptoms and increased health care utilization. ${ }^{1}$ Because of their long pharmacokinetic half-lives, long-acting injectable (LAI) formulations of antipsychotic medications may help manage these challenges in some patients. ${ }^{1}$

In recent years, a number of LAIs have become available for patient use. ${ }^{1}$ However, information on the comparative effectiveness and costs of using these LAIs versus oral antipsychotics (OAs) is not available. The population effectiveness of using these treatments is also not known.

There is growing demand for evidence that any new health technology, whose efficacy is often established in controlled clinical trials, is effective when applied to the real world. ${ }^{2}$ This is especially true for payers, who are confronted with covering high costs for such technologies without evidence that plan beneficiaries will derive commensurate benefits from the technology. ${ }^{3}$ Public and private research is needed to generate such evidence, and several initiatives are under way to develop 


\section{Projecting the Potential Effect of Using Paliperidone Palmitate Once-Monthly and Once-Every-3-Months Long-Acting Injections Among Medicaid Beneficiaries with Schizophrenia}

real-world data assets that can fill the gap (http://www.pcornet. org; http://apcdcouncil.org).

While traditional methods to generate real-world evidence are well established, such as pragmatic trial designs and observational data methods, ${ }^{4,5}$ they require significant time and resources. For example, the large pragmatic trials needed to produce real-world evidence can take several years, ${ }^{2}$ thereby delaying access to newer therapies. While generating such evidence is valuable for payers to make optimal decisions about access, real-world evidence could be projected from existing data for some therapies without having to conduct a new realworld study. ${ }^{6,7}$

The objective of this study was to develop a decision model, informed by patient-level data available from 3 randomized clinical trials with long-acting formulations of paliperidone palmitate ( 2 phase 3 trials and a limited real-world phase $3 \mathrm{~b}$ study). These data were used to project the effect of using paliperidone palmitate once-monthly (PP1M) and once-every3-months (PP3M) LAI formulations on psychiatric (Psych) and all-cause (AC) hospitalization rates over a period of 18 months in patients with schizophrenia receiving Medicaid and being treated with OAs. We monetized these effects using the potential size of the target population in Medicaid and the average costs of hospitalization.

\section{Methods}

\section{Data Sources}

Efficacy and effectiveness data for PP1M and PP3M were obtained from 3 different randomized controlled trials. The first trial, PRIDE (NCT01157351), was a 15-month prospective, real-world, randomized, comparative study of daily OAs (1 of the following 7 acceptable, prespecified OAs was used: aripiprazole, haloperidol, olanzapine, paliperidone, perphenazine, quetiapine, and risperidone) and PP1M in patients with schizophrenia who had recent involvement with the criminal justice system. ${ }^{5}$ The PRIDE study design incorporated both explanatory (efficacy) and pragmatic (effectiveness) design elements, allowing analysis of efficacy and effectiveness outcomes. ${ }^{5}$ The primary outcome measure was time to first treatment failure, the definition of which included arrest/incarceration, Psych hospitalization, or interventions to prevent treatment failure.

The second trial, 3001 (NCT00111189), was a randomized, double-blind, discontinuation relapse-prevention study that compared the efficacy and tolerability of PP1M to those of placebo among patients with schizophrenia who had been stabilized (Positive and Negative Syndrome Scale [PANSS] total score $\leq 75)$ on PP1M for 3 months. ${ }^{8}$ The third trial, 3012 (NCT01529515), was a randomized, double-blind, relapseprevention study that compared the efficacy and tolerability of PP3M with those of placebo among patients with schizophrenia who were stabilized (PANSS total score $<70$ ) on PP1M for 4 months. ${ }^{9}$ The primary outcome measure for the latter 2 studies was time to first relapse during the double-blind phase, the definition of which included significant deterioration in clinical symptoms as measured by PANSS or hospitalization for symptoms of schizophrenia.

Real-world data for 2009 through 2013 were obtained from the Truven Multi-State Medicaid claims database. Inclusion and exclusion criteria from PRIDE (Appendix A, available in online article) were applied to identify OA-treated Medicaid beneficiaries in the Truven database. The main inclusion criteria included identifying patients who enrolled in Medicaid during 2009-2013, had at least 1 service with schizophrenia International Classification of Diseases, Ninth Revision, Clinical Modification (ICD-9-CM) code 295.xx within 90 days after enrollment, and had at least 1 antipsychotic prescription within 90 days of enrollment. We approximated data from the more real-world PRIDE population by including only those patients who initiated OA (index) within 90 days of enrollment in the Medicaid sample. As our decision model progressed, we mirrored the population targeted by trials 3001 and 3012 by identifying patients who were stabilized on OA for 6 months.

\section{Decision Model}

A decision model, informed by PRIDE, 3001, and 3012 trial data, was developed to compare 3 treatment strategies (Figure 1). The first treatment strategy was initiating with $\mathrm{OA}$ and switching to another OA. Because each index OA was not modeled separately, a weighted average of initiating with various index OAs (aripiprazole, haloperidol, olanzapine, paliperidone, perphenazine, quetiapine, or risperidone) was used (i.e., the weights were based on the observed distribution of use of these index drugs in the Medicaid sample). Treatment switches could be to any other OA, including long-acting drugs, provided that the long-acting drugs were not initiated 90 days before the index $\mathrm{OA}$ date.

The second treatment strategy was initiating PP1M and continuing on PP1M if the patient was stabilized at 6 months $(\mathrm{PP} 1 \mathrm{M} \rightarrow \mathrm{PP} 1 \mathrm{M})$. Those who discontinued PP1M within the first 6 months after initiation were switched back to receive $\mathrm{OA}$. The remaining subjects continued to use PPIM. The third treatment strategy was initiating PP1M and switching to PP3M if the patient was stabilized at 6 months $(\mathrm{PP} 1 \mathrm{M} \rightarrow \mathrm{PP} 3 \mathrm{M})$. Those who discontinued PP1M within the first 6 months after initiation were switched back to receive OA. The remaining subjects were switched to PP3M at the 6-month mark.

\section{Statistical Analyses}

Novel propensity score-based methods were used to assess the generalizability of PRIDE, 3001, and 3012 clinical trial data and extrapolate trial results to those of the Medicaid sample..$^{10-13}$ Our analysis had 5 steps (Figure 2). The first step was to construct a propensity score model by comparing baseline characteristics of patients in the OA arm of the PRIDE trial 
Projecting the Potential Effect of Using Paliperidone Palmitate Once-Monthly and Once-Every-3-Months Long-Acting Injections Among Medicaid Beneficiaries with Schizophrenia

\section{FIGURE 1 Decision Model}

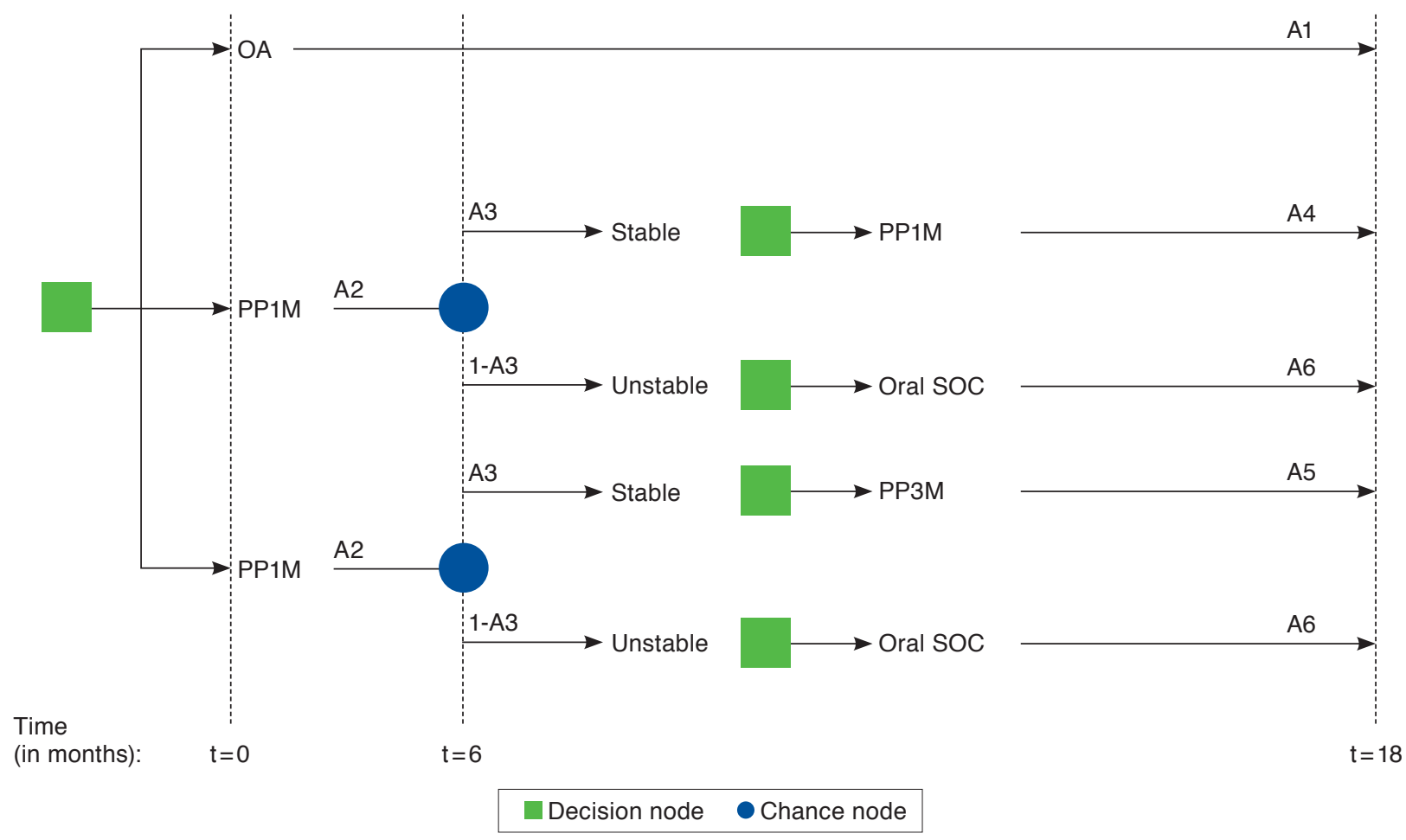

\begin{tabular}{l|l|l|c|c|c|c}
\hline Parameters & \multicolumn{1}{|c|}{ Description } & \multicolumn{1}{|c|}{ Source Data } & Source & Psych & All-Cause & Distribution \\
\hline A1 & 18-month events with OA prescription & PRIDE projected onto Medicaid & Table 2 & $0.50(0.28)$ & $0.59(0.28)$ & Normal \\
\hline A2 & First 6-month events with PP1M & PRIDE projected onto Medicaid & Table 2 & $0.08(0.04)$ & $0.13(0.04)$ & Normal \\
\hline A3 & Probability (stable at 6 months with PP1M) & PRIDE projected onto Medicaid & Table 2 & $0.60(0.04)$ & $0.60(0.04)$ & Beta \\
\hline A4 & $\begin{array}{l}\text { 7-to 18-month events with PP1M among } \\
\text { stable population }\end{array}$ & Trial 3001 projected onto Medicaid & Table 4 & $0.11(0.05)$ & $0.11(0.05)$ & Gamma \\
\hline A5 & $\begin{array}{l}\text { 7-to 18-month events with PP3M among } \\
\text { stable population }\end{array}$ & Trial 3012 projected onto Medicaid & Table 4 & $0.04(0.045)$ & $0.05(0.05)$ & Gamma \\
\hline A6 & $\begin{array}{l}\text { 7-to 18-month events with OA } \\
\text { prescription among unstable population }\end{array}$ & Observed Medicaid data & Table 2 & $0.20(0.03)$ & $0.29(0.04)$ & Gamma \\
\hline
\end{tabular}

$\mathrm{OA}=$ oral antipsychotic; $P P 1 \mathrm{M}=$ once-monthly long-acting injectable paliperidone palmitate; $P P 3 \mathrm{M}=$ once-every-3-months long-acting injectable paliperidone palmitate; $S O C=$ standard of care.

versus those in the Medicaid sample and by calculating the probability of belonging to the Medicaid sample conditional on these baseline characteristics. The propensity score was based on age, gender, and race categories as well as preperiod time (time between enrollment and index date), use of Psych and AC hospitalizations during the preperiod time, and distribution of specific OAs used at initiation.

The average number of trial-defined Psych and AC hospitalizations within 15 months of initiating an $\mathrm{OA}$ among patients in the PRIDE oral arm was reweighted with the inverse probability weighting (IPW), using the estimated propensity scores to project to those in the Medicaid sample who initiated OA.
The 15-month projected estimates were prorated to reflect 18-month estimates and were compared with observed utilization rates of Psych and AC hospitalization of those in the Medicaid sample who initiated OA. A validation exercise was performed (see Validation Exercises section under this heading). Similar methods were used to reweight the probability of OA discontinuation observed in the PRIDE data to project the potential probability of $\mathrm{OA}$ discontinuation in the Medicaid population within the first 6 months of initiation.

The second step was to construct a second propensity score model that reflected the probability of belonging to a Medicaid cohort compared with the PP1M arm of the PRIDE trial. The 
Projecting the Potential Effect of Using Paliperidone Palmitate Once-Monthly and

Once-Every-3-Months Long-Acting Injections Among Medicaid Beneficiaries with Schizophrenia

FIGURE 2 Methodological Steps Followed to Generate Projection to Medicaid
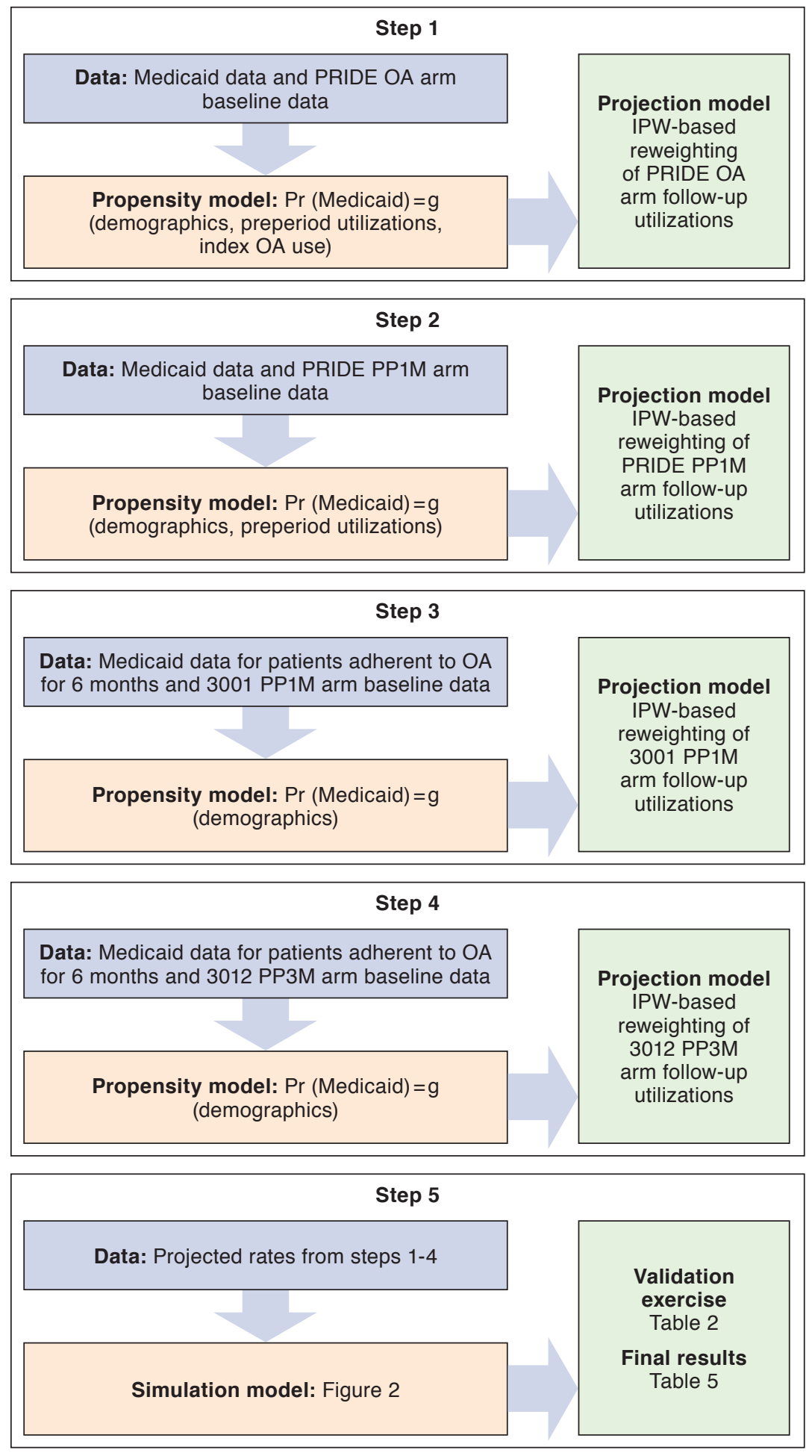

Note: Data for the decision model were drawn from PRIDE, 3001, and 3012 trials.,5,9

$I P W=$ inverse probability weighting based on estimated propensity scores; $O A=$ oral antipsychotic; PPIM= once-monthly long-acting injectable paliperidone palmitate; PP3M = once-every-3-months long-acting injectable paliperidone palmitate; $\mathrm{Pr}=$ probability. 


\section{Projecting the Potential Effect of Using Paliperidone Palmitate Once-Monthly and Once-Every-3-Months Long-Acting Injections Among Medicaid Beneficiaries with Schizophrenia}

propensity score was based on levels of age, gender, and race categories and on preperiod duration and utilization levels of Psych and AC hospitalizations during the preperiod time. Using IPW, the average number of Psych and AC hospitalizations within the first 6 months of receiving PP1M among patients enrolled in the PRIDE PPIM trial arm was projected to the Medicaid sample to reflect what the potential utilization rates would have been if the patients had initiated with PP1M. Similar methods were used to project the probability of PP1M discontinuation within the first 6 months of initiation.

The third step was to construct a third propensity score model reflecting the probability of belonging to Medicaid compared with the PPIM arm of trial 3001. Here, the Medicaid sample comprised those who would have continued their initial OA for at least 6 months, representing the stable population in trial 3001. The propensity score was based on levels of age, gender, and race categories. Using IPW, the average number of Psych and AC hospitalizations within the first 12 months of receiving PP1M among the stabilized patients in the PP1M arm of trial 3001 was projected to the stabilized patients in the Medicaid sample to reflect what the potential utilization rates would have been if they had initiated PP1M and continued receiving PP1M.

The fourth step was to construct a fourth propensity score model reflecting the probability of belonging to Medicaid compared with the PP3M arm of trial 3012. Here again, the Medicaid sample comprised those who would have continued their initial OA for at least 6 months; these patients represented the stable population in trial 3012 . The propensity score was based on levels of age, gender, and race categories. Using IPW, the average number of Psych and AC hospitalizations within the first 12 months of receiving PP3M (i.e., patients in trial 3012 who were stabilized on PP1M for 6 months and then randomly assigned to $\mathrm{PP} 3 \mathrm{M}$ ) were projected to the stabilized patients in the Medicaid sample to reflect what the potential utilization rates would have been if they had initiated PP1M and continued receiving PP3M.

For steps 1 through 4, the modeling of utilizations accounted for censoring within corresponding trial data. Typically, IPW is used to account for censoring. ${ }^{14,15}$ However, because another set of weights was used for projection, a pattern mixture modeling approach was used to deal with censoring ${ }^{7,16}$; in this approach, a simple regression of utilization outcome on time to followup, the censoring indicator, and the interaction between these 2 approaches was used. Expected utilizations were estimated for 18 months (step 1), 6 months (in step 2), and 12 months poststabilization (steps 3 and 4) of follow-up.

The standard errors (SEs) for each projected parameter in our analyses were estimated based on 1,000 bootstrapped replicates on the corresponding analytical sample. All analyses were performed using Stata software package 13.0 (StataCorp, College Station, TX).

\section{Probabilistic Simulation Model}

Results from steps 1 through 4 were pooled in a fully probabilistic simulation model that compared 18-month utilization rates in the Medicaid sample for each of the 3 treatment strategies. The probabilistic simulation model incorporated all sources of uncertainty in parameter estimates. The distributional assumptions for each parameter are given in Figure 1.

The source of evidence for parameters A1 to A5 are given in Figure 1. We derived an estimate for parameter A6, which represents the 7- to 18-month utilizations among patients receiving $\mathrm{OA}$ who were unstable (i.e., discontinued their index medication within the first 6 months), based on observed Medicaid data (Figure 1). Differences between 18-month and 6-month utilizations in this group of unstable patients were defined as follows: $(\mathrm{N}=4,609 \times[1-0.39]=2,795 ; \mathrm{AC}: 1.01-0.72=0.29$; Psych: $0.64-0.44=0.20$ ). The SE for this derived parameter was based on 1,000 bootstrap replicates.

\section{Validation Exercises}

The first validation exercise compared propensity score-based projections of the PRIDE oral arm utilization data to the Medicaid sample with those of the observed utilization rates of Psych and AC hospitalizations in the Medicaid sample. Similarity in the projected and observed utilization rates confirmed the generalizability of these approaches to reflect outcomes in the Medicaid sample.

The second validation exercise compared the projected results from the PP1M $\rightarrow$ PPIM arm to the projected 18-month results from the PRIDE PPIM. Similarity between these results indicated replicability of the decision model results that combined information from various sources to that of a pragmatic trial when both sets of results were projected to reflect the Medicaid sample.

\section{Quantification of Effect on Hospital Rates in U.S. Dollars}

The monetary quantification of the effect of PP1M and PP3M treatment strategies on hospitalization rates was based on a total Medicaid population of 62 million and a cost of $\$ 10,000$ per AC hospitalization..$^{17,18}$ The target population was calculated by multiplying the exclusion rate in the Medicaid data used in this study (Appendix A; 4,609/232,016=1.98\%) to the total Medicaid population. Therefore, monetization of hospitalization effect was calculated as the following:

$$
\begin{gathered}
\$=62 \text { million } \times 1.98 \% \times \$ 10,000 \times \text { reduction } \\
\text { in average number of hospitalizations }
\end{gathered}
$$

\section{Results}

The PRIDE inclusion and exclusion criteria were applied to the individual-level data from patients enrolled in Medicaid managed care between 2009 and 2013. Our final real-world sample size was 4,609 (Appendix A). Individual-level characteristics 


\section{Projecting the Potential Effect of Using Paliperidone Palmitate Once-Monthly and Once-Every-3-Months Long-Acting Injections Among Medicaid Beneficiaries with Schizophrenia}

TABLE 1 Projected Outcomes of PRIDE Trial Patients onto the Medicaid Patient Sample

\begin{tabular}{|c|c|c|c|c|c|c|c|c|c|}
\hline \multirow[b]{2}{*}{ Outcomes } & \multicolumn{4}{|c|}{ PRIDE Trial (Observed)a } & \multirow{2}{*}{\begin{tabular}{c|}
$\begin{array}{c}\text { Medicaid } \\
\text { (Observed)a }\end{array}$ \\
OA \\
$\mathrm{n}=4,609$
\end{tabular}} & \multicolumn{4}{|c|}{ PRIDE Trials (Projected) ${ }^{b}$} \\
\hline & $\begin{array}{c}\mathrm{OA} \\
\mathrm{n}=212\end{array}$ & $\begin{array}{c}\text { PP1M } \\
\mathrm{n}=219\end{array}$ & Difference & $\begin{array}{l}P \text { Value } \\
(95 \% \text { CI) }\end{array}$ & & $\begin{array}{c}\mathrm{OA} \\
\mathrm{n}=212\end{array}$ & $\begin{array}{l}\text { PP1M } \\
\mathrm{n}=219\end{array}$ & Difference & $\begin{array}{l}P \text { Value } \\
(95 \% \mathrm{CI})\end{array}$ \\
\hline \multicolumn{10}{|c|}{ Hospitalizations over 18 months (full sample), $n$} \\
\hline AC, mean (SE) & $\begin{array}{c}0.55 \\
(0.15)\end{array}$ & $\begin{array}{c}0.37 \\
(0.09)\end{array}$ & $\begin{array}{c}0.18 \\
(0.18)\end{array}$ & $\begin{array}{c}0.317 \\
(-0.17-0.53)\end{array}$ & $\begin{array}{c}0.83 \\
(0.04)\end{array}$ & $\begin{array}{c}0.59 \\
(0.28)\end{array}$ & $\begin{array}{c}0.40 \\
(0.15)\end{array}$ & $\begin{array}{c}0.19 \\
(0.32)\end{array}$ & $\begin{array}{c}0.552 \\
(-0.43-0.82)\end{array}$ \\
\hline Psych, mean (SE) & $\begin{array}{c}0.42 \\
(0.15) \\
\end{array}$ & $\begin{array}{c}0.22 \\
(0.07) \\
\end{array}$ & $\begin{array}{c}0.20 \\
(0.18) \\
\end{array}$ & $\begin{array}{c}0.267 \\
(-0.15-0.55) \\
\end{array}$ & $\begin{array}{c}0.50 \\
(0.03) \\
\end{array}$ & $\begin{array}{c}0.50 \\
(0.28) \\
\end{array}$ & $\begin{array}{c}0.24 \\
(0.09) \\
\end{array}$ & $\begin{array}{c}0.26 \\
(0.29) \\
\end{array}$ & $\begin{array}{c}0.370 \\
(-0.31-0.83) \\
\end{array}$ \\
\hline \multicolumn{10}{|c|}{ Among patients who discontinued by 6 months } \\
\hline AC, mean (SE) & - & - & - & & $\begin{array}{l}1.01 \\
(0.05)\end{array}$ & - & - & - & \\
\hline Psych, mean (SE) & - & - & - & & $\begin{array}{c}0.64 \\
(0.06) \\
\end{array}$ & - & - & - & \\
\hline \multicolumn{10}{|c|}{ Hospitalizations over 6 months (full sample), $n$} \\
\hline AC, mean (SE) & $\begin{array}{c}0.42 \\
(0.13) \\
\end{array}$ & $\begin{array}{c}0.19 \\
(0.05) \\
\end{array}$ & $\begin{array}{c}0.23 \\
(0.15) \\
\end{array}$ & $\begin{array}{c}0.125 \\
(-0.06-0.52) \\
\end{array}$ & $\begin{array}{c}0.64 \\
(0.02) \\
\end{array}$ & $\begin{array}{c}0.44 \\
(0.17) \\
\end{array}$ & $\begin{array}{c}0.13 \\
(0.04) \\
\end{array}$ & $\begin{array}{c}0.31 \\
(0.17) \\
\end{array}$ & $\begin{array}{c}0.068 \\
(-0.02-0.64) \\
\end{array}$ \\
\hline Psych, mean (SE) & $\begin{array}{c}0.37 \\
(0.13)\end{array}$ & $\begin{array}{c}0.11 \\
(0.04)\end{array}$ & $\begin{array}{c}0.26 \\
(0.14)\end{array}$ & $\begin{array}{c}0.063 \\
(-0.01-0.53)\end{array}$ & $\begin{array}{c}0.38 \\
(0.03)\end{array}$ & $\begin{array}{l}0.38 \\
(0.16)\end{array}$ & $\begin{array}{c}0.08 \\
(0.04)\end{array}$ & $\begin{array}{c}0.30 \\
(0.16)\end{array}$ & $\begin{array}{c}0.061 \\
(-0.01-0.61)\end{array}$ \\
\hline \multicolumn{10}{|c|}{ Among patients who discontinued by 6 months } \\
\hline $\mathrm{AC}$, mean $(\mathrm{SE})$ & - & - & - & & $\begin{array}{c}0.72 \\
(0.03)\end{array}$ & - & - & - & \\
\hline Psych, mean (SE) & - & - & - & & $\begin{array}{c}0.44 \\
(0.02)\end{array}$ & - & - & - & \\
\hline $\begin{array}{l}\text { Probability of continuation } \\
\geq 6 \text { months }\end{array}$ & $\begin{array}{l}0.47 \\
(0.03)\end{array}$ & $\begin{array}{c}0.59 \\
(0.03)\end{array}$ & $\begin{array}{l}-0.12 \\
(0.04) \\
\end{array}$ & $\begin{array}{c}0.003 \\
(-0.20-0.04) \\
\end{array}$ & $\begin{array}{c}0.39 \\
(0.01)\end{array}$ & $\begin{array}{l}0.46 \\
(0.05) \\
\end{array}$ & $\begin{array}{l}0.60 \\
(0.04)\end{array}$ & $\begin{array}{l}-0.14 \\
(0.06)\end{array}$ & $\begin{array}{c}0.020 \\
(-0.02-0.26)\end{array}$ \\
\hline \multicolumn{10}{|c|}{ Time to discontinuation over 15 months, days } \\
\hline Full sample, mean (SE) & $\begin{array}{l}155 \\
(13)\end{array}$ & $\begin{array}{l}245 \\
(19)\end{array}$ & $\begin{array}{l}-90 \\
(23)\end{array}$ & $\begin{array}{l}<0.001 \\
(45-135)\end{array}$ & $\begin{array}{l}149 \\
(7)\end{array}$ & $\begin{array}{l}153 \\
(17)\end{array}$ & $\begin{array}{l}240 \\
(23)\end{array}$ & $\begin{array}{l}-87 \\
(29)\end{array}$ & $\begin{array}{c}0.003 \\
(-30-144)\end{array}$ \\
\hline $\begin{array}{l}\text { Among patients who did not dis- } \\
\text { continue by } 6 \text { months, mean (SE) }\end{array}$ & - & - & - & & $\begin{array}{l}374 \\
(6)\end{array}$ & - & - & - & \\
\hline \multicolumn{10}{|c|}{ Time to discontinuation over 18 months, days } \\
\hline Full sample, mean (SE) & - & - & - & & $\begin{array}{c}154 \\
(7)\end{array}$ & - & - & - & \\
\hline $\begin{array}{l}\text { Among patients who did not dis- } \\
\text { continue by } 6 \text { months, mean (SE) }\end{array}$ & - & - & - & & $\begin{array}{c}400 \\
(6) \\
\end{array}$ & - & - & - & \\
\hline \multicolumn{10}{|c|}{$\begin{array}{l}\text { Note: A dash means not enough sample size for estimation. } \\
\text { aAdjusted for censoring. } \\
\text { bAdjusted for censoring and projected to reflect the Medicaid sample; standard errors obtained via 1,000 bootstrap replicates. } \\
\text { AC=all-cause; } C I=\text { confidence interval; } O A=\text { oral antipsychotic; PPIM= once-monthly long-acting injectable paliperidone palmitate; Psych=psychiatric; SE=standard error. }\end{array}$} \\
\hline
\end{tabular}

from the 2 arms (OA versus PPIM) of the PRIDE trial, the observed Medicaid data, and the projected characteristics of the PRIDE trial after reweighting aligned well with the Medicaid data (Appendix B, available in online article). Data from 212 PRIDE OA and 219 PRIDE PPIM patients were used to estimate the change in hospitalization outcomes for 4,609 Medicaid OA patients as if they had been treated with PPIM. Compared with PRIDE, the Medicaid sample was older $(P<0.010)$, more female and white $(P<0.001)$, and less black and Hispanic (Appendix B). Distribution of $\mathrm{OA}$ products differed significantly between PRIDE OA and Medicaid OA at index $(P<0.001)$.

Reweighting outcomes from PRIDE data to those of the Medicaid sample resulted in the average number of Psych hospitalizations at 18 months and 6 months to match closely with those observed in the Medicaid sample, thus validating the approach (Table 1). For AC hospitalization rates, reweighted estimates were lower than those in the Medicaid sample; this likely made our incremental estimate of long-acting paliperidone palmitate strategies a conservative one. Projected 6-month and 18-month absolute and incremental effects of PP1M are shown in Table 1. At 6 months, projected PRIDE PPIM mean Psych and AC hospitalizations per patient were estimated to be lower than projected PRIDE OA hospitalizations per patient by 0.30 (95\% confidence interval $[\mathrm{CI}]=-0.01-0.61 ; \mathrm{SE}=0.16$; $P=0.061)$ and $0.31(95 \% \mathrm{CI}=-0.02-0.64 ; \mathrm{SE}=0.17 ; P=0.068)$, respectively. An additional 14\% (95\% CI=2\%-26\%; SE=6.0; 


\section{Projecting the Potential Effect of Using Paliperidone Palmitate Once-Monthly and Once-Every-3-Months Long-Acting Injections Among Medicaid Beneficiaries with Schizophrenia}

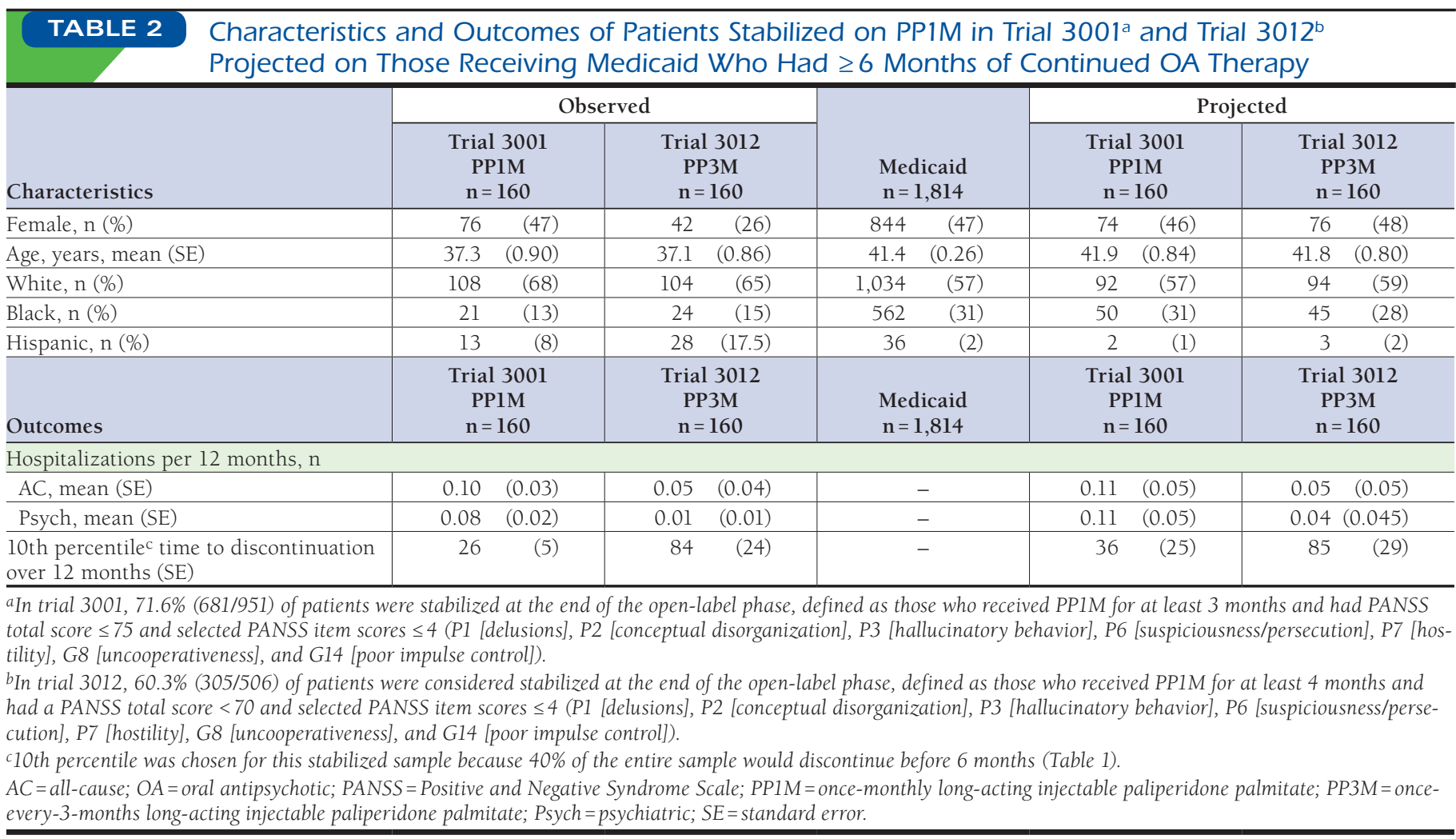

$P<0.050)$ of this sample would have continued with medication at 6 months if treated with PP1M.

At 18 months, mean reductions in projected Psych and AC hospitalizations for PP1M compared with OA were 0.26 (95\% CI $=-0.31-0.83 ; \mathrm{SE}=0.29 ; P=0.370)$ and $0.19(95 \% \mathrm{CI}=$ $-0.43-0.82 ; \mathrm{SE}=0.32 ; P=0.552$ ), respectively. Median time to discontinuation over a 15 -month duration in the PRIDE trial was projected to extend time on medication by 87 days (95\% CI = 30-144; $\mathrm{SE}=29 ; P=0.003$; Table 1) versus OA.

Table 2 illustrates how patient characteristics from the PP1M arm of trial 3001 and the PP3M arm of trial 3012 were made to reflect the distribution of characteristics in the Medicaid sample among the stable patients enrolled in these trials (i.e., those who continued their initial therapy for at least 6 months). Table 2 also presents the projected results from trials 3001 and 3012 to the stable Medicaid sample and reflect the projected utilizations for months $>6$ through 18 or the 12-month poststabilization date.

Results of the probabilistic simulation model are shown in Table 3. In the Medicaid sample, the PPIM $\rightarrow$ PP1M strategy was projected to produce a per patient decrease of 0.27 (95\% CI $=$ -0.43-0.97) and 0.28 (95\% CI=-0.28-0.84) in Psych- and AC-related hospitalizations, respectively, compared with initiating treatments with OA. Similarly, PP1M $\rightarrow$ PP3M was projected to produce a per patient decrease of $0.31(95 \% \mathrm{CI}=-0.27-0.87)$ in both Psych- and AC-related hospitalizations versus OA.
The absolute effect of the PP1M $\rightarrow$ PP1M strategy in our simulation was estimated to be $0.31(95 \% \mathrm{CI}=0.21-0.41 ; \mathrm{SE}=0.05$; $P<0.001)$ and 0.23 (95\% CI=0.13-0.33; $\mathrm{SE}=0.05 ; P<0.001$ ) for AC- and Psych-related hospitalizations, respectively (Table 3). This matched well with the projected PRIDE results for the PP1M intention-to-treat arm of 0.40 (95\% CI $=0.11-0.69$; $\mathrm{SE}=0.15 ; P=0.008)$ and $0.24(95 \% \mathrm{CI}=0.06-0.42 ; \mathrm{SE}=0.09$; $P<0.001)$, respectively, and thereby validated our results. Only data from the first 6 months of the PRIDE trial were used in our simulation model; 7 - to 18-month data were obtained from the other trials.

The incremental estimates reported in Table 3 were used to calculate potential savings for the total Medicaid population of 62 million. ${ }^{17}$ Based on our exclusion and inclusion criteria (Appendix A), the target sample size would be 1.23 million $([4,609 / 232,016] \times 62$ million). Assuming a cost of $\$ 10,000$ per AC hospitalization, following the PP1M $\rightarrow$ PPlM strategy for 18 months would eliminate 344,400 AC hospitalizations amounting to $\$ 3.4$ billion. $^{18}$ Similarly, following the PP1M $\rightarrow$ PP3M strategy for 18 months would eliminate 381,300 AC hospitalizations amounting to $\$ 3.8$ billion.

\section{Discussion}

Worldwide there is tremendous interest in real-world data and evidence in health care. However, conducting large 


\section{Projecting the Potential Effect of Using Paliperidone Palmitate Once-Monthly and Once-Every-3-Months Long-Acting Injections Among Medicaid Beneficiaries with Schizophrenia}

\section{TABLE 3 Probabilistic Decision Model Evaluating Outcomes Projected to Medicaid Sample}

Across 3 Treatment Strategies Over 18 Months

\begin{tabular}{|c|c|c|c|c|c|c|}
\hline Outcomes & $\mathrm{OA}$ & $\mathrm{PP} 1 \mathrm{M} \rightarrow \mathrm{PP} 1 \mathrm{M}$ & $\mathrm{PP} 1 \mathrm{M} \rightarrow \mathrm{PP} 3 \mathrm{M}$ & $\begin{array}{c}\text { OA } \\
(\mathrm{PP} 1 \mathrm{M} \rightarrow \mathrm{PP} 1 \mathrm{M}) \\
\text { Mean }(\mathrm{SE}), \\
\text { P Value }(95 \% \mathrm{CI})\end{array}$ & $\begin{array}{c}\text { OA } \\
(\mathrm{PP} 1 \mathrm{M} \rightarrow \mathrm{PP} 3 \mathrm{M}) \\
\text { Mean }(\mathrm{SE}), \\
P \text { Value }(95 \% \mathrm{CI})\end{array}$ & $\begin{array}{c}(\mathrm{PP} 1 \mathrm{M} \rightarrow \mathrm{PP} 1 \mathrm{M}) \\
(\mathrm{PP} 1 \mathrm{M} \rightarrow \mathrm{PP} 3 \mathrm{M}) \\
\text { Mean }(\mathrm{SE}) \\
\text { P Value }(95 \% \mathrm{CI})\end{array}$ \\
\hline \multicolumn{7}{|l|}{ Hospitalizations } \\
\hline Psych, mean (SE) & $0.50 \quad(0.28)$ & $0.23(0.05)$ & $0.19(0.05)$ & $\begin{array}{c}0.27(0.35) \\
0.440(-0.43-0.97) \\
\end{array}$ & $\begin{array}{c}0.31(0.28) \\
0.268(-0.43-0.97)\end{array}$ & $\begin{array}{c}0.04(0.07) \\
0.568(-0.10-0.18)\end{array}$ \\
\hline $\mathrm{AC}$, mean $(\mathrm{SE})$ & $0.59(0.28)$ & $0.31 \quad(0.05)$ & $0.28 \quad(0.05)$ & $\begin{array}{c}0.28(0.28) \\
0.317(-0.28-0.84)\end{array}$ & $\begin{array}{c}0.31(0.28) \\
0.268(-0.27-0.87) \\
\end{array}$ & $\begin{array}{c}0.03(0.07), 0.668 \\
(-0.11-0.17)\end{array}$ \\
\hline $\begin{array}{l}\text { Median time to } \\
\text { discontinuation, days }\end{array}$ & $153(17)^{\mathrm{a}}$ & $206 \quad(24)$ & $265 \quad(29)$ & - & - & $\begin{array}{c}-59(38) \\
0.121(-15-133) \\
\end{array}$ \\
\hline
\end{tabular}

a 15 months and so is not directly comparable to other estimates.

$A C=$ all-cause $; C I=$ confidence interval $; O A=$ oral antipsychotic $;$ Psych = psychiatric; PP1M=once-monthly long-acting injectable paliperidone palmitate; PP3M=once-

every-3-months long-acting injectable paliperidone palmitate; SE= standard error.

studies to generate real-world evidence takes substantial time and resources. Therefore, obtaining signals from current clinical trial data on the projected and validated effect in real-world populations could be very useful. In this study, which was based on recent developments in reweighting methods, we projected the potential effect of patient-level data from 3 phase 3/3b clinical trials to reflect the real-world Medicaid population based on several patient characteristics. To our knowledge, this is the first attempt to project a decision model drawing from different patient-level clinical trial data sources to those of a real-world population. We applied decision modeling to understand the potential real-world effect of using paliperidone palmitate LAIs over OAs in patients with schizophrenia.

Schizophrenia represents one of the most debilitating mental health illnesses in humans. Patients with this disorder are primarily treated with antipsychotic medications because of their efficacy in the treatment of delusions, hallucinations, mood instability, negative symptoms, and cognitive impairment $^{1,19}$; this often results in significant functional improvement and a major public health benefit. A recent study by Fitch et al. (2014) estimated that in 2013 the average per patient per month cost of a patient with schizophrenia was $\$ 1,806,20$ which translates to a total cost of $\$ 40$ billion over 18 months in our target Medicaid population. Of the per patient per month cost of $\$ 1,806,42 \%$ was based on inpatient expenditures. ${ }^{20}$ In a cost analysis study conducted by Wu et al. (2005), hospitalizations were found to be a major cost driver for patients with schizophrenia. ${ }^{21}$

Nonadherence to antipsychotic medication has been shown to account for $40 \%$ of relapses in schizophrenia, and nonadherent patients with schizophrenia are 2.5 times more likely to have a Psych hospitalization than those who are adherent. ${ }^{22-26}$ Successful care transition and continuous exposure to appropriate medication therapy are important factors that can help reduce the risk of relapse. ${ }^{27-29}$ However, in the 2008 CATIE study, $74 \%$ of study participants discontinued their study medication, and the median time to medication discontinuation was 4.6 months. ${ }^{30}$

Our results validate the CATIE study results and suggest that over an 18-month period, patients receiving OA discontinue medication after 153 days ( 5 months), whereas patients receiving $\mathrm{PP} 1 \mathrm{M} \rightarrow \mathrm{PP} 1 \mathrm{M}$ or $\mathrm{PP} 1 \mathrm{M} \rightarrow \mathrm{PP} 3 \mathrm{M}$ treatment experienced longer time to medication discontinuation (206 days and 265 days, respectively). Furthermore, during this 18-month period, switching from OA to PP1M or PP3M (with patients who fail to continue on PP1M or PP3M for 6 months switching back to $\mathrm{OA}$ ) could produce substantial reductions in Psych and AC hospitalizations that are worth between $\$ 3.4$ and $\$ 3.8$ billion. This finding is particularly noteworthy given that schizophrenia is a costly disease.

A cost analysis based on private and public (Medicaid) claims databases found that the overall U.S. 2002 cost of schizophrenia was estimated to be $\$ 62.7$ billion. Of this $\$ 62.7$ billion, $\$ 22.7$ billion was attributed to excess direct health care costs ( $\$ 7.0$ billion outpatient, $\$ 5.0$ billion drugs, $\$ 2.8$ billion inpatient, and $\$ 8.0$ billion long-term care); $\$ 7.6$ billion was attributed to direct nonhealth care excess costs; and $\$ 32.4$ billion was attributed to indirect excess costs. ${ }^{21}$ Although cost reduction is important for reducing the economic burden of schizophrenia, perhaps more significant to the patient are the clinical benefits of continuous exposure to antipsychotic medication, which reduces the risk for relapse and its negative consequences, provides sustained symptom control, and optimizes clinical and psychosocial outcomes. ${ }^{31,32}$

Growing real-world evidence supports the premise that LAI antipsychotic use in routine clinical practice provides both clinical and economic benefits in patients with schizophrenia. ${ }^{33-37}$ Findings from recent claims database analyses and retrospective cohort studies have shown that, compared with $\mathrm{OA}$, initiation of LAIs improves adherence and persistence, 


\section{Projecting the Potential Effect of Using Paliperidone Palmitate Once-Monthly and Once-Every-3-Months Long-Acting Injections Among Medicaid Beneficiaries with Schizophrenia}

increases symptomatic remission, reduces treatment discontinuation, and decreases health care resource utilization and medical costs. ${ }^{33-37}$ In the PRIDE study, $95.2 \%$ of patients receiving PP1M had a medication possession ratio (MPR) of $>80 \%$ (based on injection records). ${ }^{5}$ This level of adherence was markedly higher than those receiving OA. By comparison, the proportion of OA patients with MPR $>80 \%$ was $77.2 \%$ when assessed with prescription records and $24.3 \%$ when assessed with refill records. ${ }^{5}$

In agreement with the results of our decision model study, a recent claims database analysis showed that LAI use is associated with significantly lower odds of rehospitalization (adjusted odds ratio $=0.73 ; 95 \% \mathrm{CI}=0.54-0.99 ; P=0.041$ ) compared with OA use. ${ }^{37}$ Although LAIs are associated with higher pharmacy costs, total costs are similar to $\mathrm{OA},{ }^{34}$ and the lower medical costs associated with second-generation LAIs, specifically PP1M, have been shown to offset more than one half of the higher pharmacy costs. ${ }^{35}$ Findings from these studies together with our observations further reinforce the notion that the clinical benefits of LAIs may also translate into meaningful reductions in economic burden.

\section{Limitations}

One limitation of our approach is the inherent reliance on observed and common patient characteristics between the trial and real-world data in order to project outcomes to the real world. Projecting based on some observed patient characteristics could be incomplete if there are differences in unobserved characteristics between the trial and the real-world sample that affect outcomes. Since there is no direct way to account for these unobserved characteristics, the comparison of projected outcomes from trials to observed outcomes in the real world can serve as a validation exercise. We performed 2 such validation exercises to show the credibility of our results.

Another major limitation is the integration of data from trials that had very different designs. For example, the 3001 and 3012 trials were global trials that were conducted in countries where service delivery was different from that in the United States. On the other hand, PRIDE was conducted in the United States as a long-term comparator study in patients who came from real-world settings. The requirement for a recent incarceration in PRIDE may have limited the generalizability of experience with this clinical trial population. However, our modeling data support the generalizability of those results despite differences in certain demographic characteristics.

Projecting trial results to a larger and more heterogeneous population increases uncertainty in the projection estimates. Our incremental effects_though substantial_-did not reach statistical significance. However, the fact that we could replicate the point estimate of the PP1M strategy by projecting the full data from the PRIDE trial indicated that the real-world effect reported from our simulation model is less likely to be due to type I error. Our effect size indicates that long-term paliperidone palmitate strategies could save 1 hospitalization per 3 patients over an 18-month period, something we believe to be both clinically and economically important.

Based on this effect-size estimate, future studies would need sample sizes of more than 10,000 patients per arm to have the power to detect statistical significance. As adoption of these long-acting strategies improves, it would provide us with a large-scale, quasi-experimental opportunity to replicate the findings from this study.

\section{Conclusions}

Projection results suggest that using PP1M and PP3M treatment strategies for patients with schizophrenia receiving Medicaid could result in reduced hospitalizations. These findings, along with improvement to patients' health, should be considered when assessing the value of these LAIs.

\section{Authors}

ANIRBAN BASU, PhD, The Comparative Health Outcomes, Policy, and Economics (CHOICE) Institute, Department of Pharmacy and the Departments of Health Services and Economics, University of Washington, Seattle. CARMELA BENSON, MS, MSHP, and LARRY ALPHS, MD, PhD, Janssen Scientific Affairs, Titusville, New Jersey.

AUTHOR CORRESPONDENCE: Anirban Basu, PhD, University of Washington, 1959 N.E. Pacific St., Box 357630, Magnuson Health Sciences Center, Room H-375Q, Seattle, WA 98195-7630.

Tel.: 206.616.2986; E-mail: basua@uw.edu.

\section{DISCLOSURES}

This study was supported by Janssen Scientific Affairs and by unrestricted funds from a consortium of 12 biomedical life sciences companies to the University of Washington. Janssen Scientific Affairs was responsible for the design and conduct of the study; the collection, management, analysis, and interpretation of data; the preparation, review, and approval of the manuscript; and the decision to submit the manuscript for publication.

Basu received financial support from Janssen Pharmaceuticals, and his time on this project was also partly covered through unrestricted gift funds from the consortium of biomedical life sciences companies. Benson and Alphs are employees of Janssen Scientific Affairs and are stockholders of Johnson $\&$ Johnson. Opinions expressed here do not necessarily reflect those of the University of Washington.

This study was presented as a poster at the AMCP Managed Care \& Specialty Pharmacy 2017 Annual Meeting; March 27-30, 2017; Denver, CO.

\section{ACKNOWLEDGMENTS}

The authors thank Mike Durkin of Janssen Scientific Affairs (Titusville, NJ) for contributing intellectually to the PRIDE data validation. The authors also thank Matt Gryzwacz, PhD, and Lynn Brown, PhD, of ApotheCom (Yardley, PA) for their writing and editorial support, which was funded by Janssen Scientific Affairs. 


\section{Projecting the Potential Effect of Using Paliperidone Palmitate Once-Monthly and Once-Every-3-Months Long-Acting Injections Among Medicaid Beneficiaries with Schizophrenia}

\section{REFERENCES}

1. Correll CU, Citrome L, Haddad PM, et al. The use of long-acting injectable antipsychotics in schizophrenia: evaluating the evidence. J Clin Psychiatry. 2016;77(Suppl 3):1-24.

2. Alphs L, Schooler N, Lauriello J. How study designs influence comparative effectiveness outcomes: the case of oral versus long-acting injectable antipsychotic treatments for schizophrenia. Schizophrenia Res. 2014;156(2-3): 228-32.

3. Lu CY. Uncertainties in real-world decisions on medical technologies. Int J Clin Pract. 2014;68(8):936-40.

4. Thorpe KE, Zwarenstein M, Oxman AD, et al. A pragmatic-explanatory continuum indicator summary (PRECIS): a tool to help trial designers. CMAJ. 2009;180(10):E47-57.

5. Alphs L, Benson C, Cheshire-Kenny K, et al. Real-world outcomes of paliperidone palmitate compared to daily oral antipsychotic therapy in schizophrenia: a randomized, open-label, review board-blinded 15-month study. J Clin Psychiatry. 2015;76(5):554-61.

6. Stuart EA, Bradshaw CP, Leaf PJ. Assessing the generalizability of randomized trial results to target populations. Prev Sci. 2015;16(3):475-85.

7. Cole SR, Stuart EA. Generalizing evidence from randomized clinical trials to target populations: the ACTG 320 trial. Am J Epidemiol. 2010;172(1):107-15

8. Hough D, Gopal S, Vijapurkar U, Lim P, Morozova M, Eerdekens M. Paliperidone palmitate maintenance treatment in delaying the time-torelapse in patients with schizophrenia: a randomized, double-blind, placebo-controlled study. Schizophr Res. 2010;116(2-3):107-17.

9. Berwaerts J, Liu Y, Gopal S, et al. Efficacy and safety of the 3-month formulation of paliperidone palmitate vs placebo for relapse prevention of schizophrenia: a randomized clinical trial. JAMA Psychiatry. 2015;72(8):830-39.

10. Imai K. Misunderstandings between experimentalists and observationalists about causal inference. J R Statist Soc A. 2008;171(part 2):481-502.

11. Greenhouse JB, Kaizar EE, Kelleher K, Seltman H, Gardner W. Generalizing from clinical trial data: a case study. The risk of suicidality among pediatric antidepressant users. Stat Med. 2008;27(11):1801-13.

12. Frangakis $C$. The calibration of treatment effects from clinical trials to target populations. Clin Trials. 2009;6(2):136-40

13. Weisberg HI, Hayden VC, Pontes VP. Selection criteria and generalizability within the counterfactual framework: explaining the paradox of antidepressant-induced suicidality? Clin Trials. 2009;6(2):109-18.

14. Bang H, Tsaitis AA. Estimating medical costs with censored data. Biometrika. 2000;87:329-43

15. Lin DY. Linear regression analysis of censored medical costs. Biostatistics. 2000;1(1):35-47.

16. Little RJA. Pattern-mixture models for multivariate incomplete data. J Am Stat Assoc. 1993;88(421):125-34

17. Centers for Medicare \& Medicaid Services. Medicaid managed care enrollment and program characteristics, 2014. Spring 2016. Available at: https://www.medicaid.gov/medicaid-chip-program-information/by-topics/ data-and-systems/medicaid-managed-care/downloads/2014-medicaid-managed-care-enrollment-report.pdf. Accessed May 26, 2018.

18. Pfuntner A, Wier LM, Elixhauser A. Overview of hospital stays in the United States, 2011. In: Healthcare Cost and Utilization Project. Statistical Brief \#166. November 2013. Available at: http://www.hcup-us.ahrq.gov/ reports/statbriefs/sb166.pdf. Accessed May 26, 2018

19. Bagnall AM, Jones L, Ginnelly L, et al. A systematic review of atypical antipsychotic drugs in schizophrenia. Health Technol Assess. 2003;7(13):1-193.
20. Fitch K, Iwasaki K, Villa KF. Resource utilization and cost in a commercially insured population with schizophrenia. Am Health Drug Benefits. 2014;7(1):18-26

21. Wu EQ, Birnbaum HG, Shi L, et al. The economic burden of schizophrenia in the United States in 2002. J Clin Psychiatry. 2005;66(9):1122-29.

22. Campagna EJ, Muser E, Parks J, Morrato EH. Methodological considerations in estimating adherence and persistence for a long-acting injectable medication. J Manag Care Spec Pharm. 2014;20(7):756-66. Available at: https://www.jmcp.org/doi/10.18553/jmcp.2014.20.7.756.

23. Gilmer TP, Dolder CR, Lacro JP, et al. Adherence to treatment with antipsychotic medication and health care costs among Medicaid beneficiaries with schizophrenia. Am J Psychiatry. 2004;161(4):692-99.

24. Weiden PJ, Mott T, Curcio N. Recognition and management of neuroleptic noncompliance. In: Shriqui CL, Nasrallah HA, eds. Contemporary Issues in the Treatment of Schizophrenia. Arlington, VA: American Psychiatric Association; 1995:411-34

25. Weiden PJ, Zygmunt A. Medication noncompliance in schizophrenia: part I, assessment. J Pract Psychiatr Behav Health. 1997;3:106-10.

26. Kane JM. Problems of compliance in the outpatient treatment of schizophrenia. J Clin Psychiatry. 1983;44:3-6.

27. Csernansky JG, Schuchart EK. Relapse and rehospitalisation rates in patients with schizophrenia: effects of second generation antipsychotics. CNS Drugs. 2002;16(7):473-84

28. van Os J, Kapur S. Schizophrenia. Lancet. 2009;374(9690):635-45.

29. Panish J, Karve S, Candrilli SD, Dirani R. Association between adherence to and persistence with atypical antipsychotics and psychiatric relapse among US Medicaid-enrolled patients with schizophrenia. J Pharm Health Serv Res. 2013;4(1):29-39.

30. Lewis S, Lieberman J. CATIE and CUtLASS: can we handle the truth? Br J Psychiatry. 2008;192(3):161-63.

31. Acosta FJ, Hemandez JL, Pereira J, Herrera J, Rodríguez CJ. Medication adherence in schizophrenia. World J Psychiatry. 2012;2(5):74-82.

32. Higashi K, Medic G, Littlewood KJ, Diez T, Granström O, De Hert M. Medication adherence in schizophrenia: factors influencing adherence and consequences of nonadherence, a systematic literature review. Ther $\mathrm{Adv}$ Psychopharmacol. 2013;3(4):200-18.

33. Joshi $\mathrm{K}$, Lafeuille $\mathrm{MH}$, Brown B, et al. Baseline characteristics and treatment patterns of patients with schizophrenia initiated on once-every-threemonths paliperidone palmitate in a real-world setting. Curr Med Res Opin. 2017;33(10):1763-72.

34. Joshi K, Lafeuille MH, Kamstra R, et al. Real-world adherence and economic outcomes associated with paliperidone palmitate versus oral atypical antipsychotics in schizophrenia patients with substance-related disorders using Medicaid benefits. J Comp Eff Res. 2018;7(2):121-33.

35. Pilon D, Tandon N, Lafeuille MH, et al. Treatment patterns, health care resource utilization, and spending in Medicaid beneficiaries initiating second-generation long-acting injectable agents versus oral atypical antipsychotics. Clin Ther. 2017;39(10):1972-85.e2.

36. Anderson JP, Icten Z, Alas V, Benson C, Joshi K. Comparison and predictors of treatment adherence and remission among patients with schizophrenia treated with paliperidone palmitate or atypical oral antipsychotics in community behavioral health organizations. BMC Psychiatry. 2017;17(1):346.

37. Marcus SC, Zummo J, Pettit AR, Stoddard J, Doshi JA. Antipsychotic adherence and rehospitalization in schizophrenia patients receiving oral versus long-acting injectable antipsychotics following hospital discharge.

J Manag Care Spec Pharm. 2015;21(9):754-68. Available at: https://www.jmcp. org/doi/10.18553/jmcp.2015.21.9.754 
Projecting the Potential Effect of Using Paliperidone Palmitate Once-Monthly and Once-Every-3-Months Long-Acting Injections Among Medicaid Beneficiaries with Schizophrenia

\begin{tabular}{|c|c|c|}
\hline Inclusion Criteria & $\begin{array}{c}\text { Patients } \\
\text { Excluded } \\
\text { n }(\%)^{\mathrm{a}}\end{array}$ & $\begin{array}{c}\text { Patients Who } \\
\text { Met Criteria } \\
\text { n (\%) }\end{array}$ \\
\hline Enrolled in Medicaid Managed Care, 2009-2013 & - & $232,016 \quad(100)$ \\
\hline Aged $18-60$ years as of January 1,2009 & $50,404 \quad(22)$ & $181,612 \quad(78)$ \\
\hline Observed to enroll during 2009-2013 (i.e., to proxy release from incarceration) & $99,882 \quad(55)$ & $81,730 \quad(45)$ \\
\hline $\begin{array}{l}\text { Restrict enrollment dates from January } 2009 \text { through June } 2012 \text { so that individual could } \\
\text { potentially have } 18 \text { months of enrollment }\end{array}$ & $12,719 \quad(16)$ & $69,011 \quad(84)$ \\
\hline Remain enrolled for at least 3 months after first instance of enrollment during 2009-2013 & 839 & $68,172 \quad(99)$ \\
\hline At least 1 service with schizophrenia ICD-9-CM code 295.xx within 90 days after enrollment & $35,987 \quad(53)$ & $32,185 \quad(47)$ \\
\hline No ICD-9-CM code for opioid dependence within 90 days after enrollment & 916 & $31,269 \quad(97)$ \\
\hline Any antipsychotic prescription within 90 days after enrollment & $24,943 \quad(80)$ & $6,326 \quad(20)$ \\
\hline No clozapine within 90 days of index date for OA prescription & 146 & $6,180 \quad(98)$ \\
\hline No injectable antipsychotics within 90 days of index date for OA prescription & 350 & $5,830 \quad(94)$ \\
\hline No oral polytherapy on index date and days supply on oral monotherapy $\geq 15$ days at index date & $1,221 \quad(21)$ & $4,609 \quad(79)$ \\
\hline
\end{tabular}

apercentage based on denominator of patients who met all previous criteria.

ICD-9-CM = International Classification of Diseases, Ninth Revision, Clinical Modification; $O A=$ oral antipsychotic.

\section{APPENDIX B Projected Characteristics of PRIDE Trial Patients onto the Medicaid Patient Sample}

\begin{tabular}{|c|c|c|c|c|c|}
\hline \multirow{3}{*}{$\begin{array}{l}\text { Characteristics } \\
\text { Female, n (\%) }\end{array}$} & \multicolumn{2}{|c|}{$\begin{array}{l}\text { PRIDE Trial } \\
\text { (Observed) }\end{array}$} & \multirow{2}{*}{\begin{tabular}{|c|} 
Medicaid (Observed) \\
OA \\
$n=4,609$
\end{tabular}} & \multicolumn{2}{|c|}{$\begin{array}{l}\text { PRIDE Trial } \\
\text { (Projected) }^{\mathrm{a}}\end{array}$} \\
\hline & $\begin{array}{c}\mathrm{OA} \\
\mathrm{n}=212\end{array}$ & $\begin{array}{c}\text { PP } \\
n=219\end{array}$ & & $\begin{array}{c}\mathrm{OA} \\
\mathbf{n}=212\end{array}$ & $\begin{array}{c}\text { PP } \\
n=219\end{array}$ \\
\hline & $25 \quad(12)$ & $33 \quad(15)$ & $2,166 \quad(47)$ & $85 \quad(40)$ & $94 \quad(43)$ \\
\hline Mean age, years & 38.6 & 37.5 & 39.5 & 39.1 & 38.0 \\
\hline White, n (\%) & $70 \quad(33)$ & $70 \quad(32)$ & $2,258 \quad(49)$ & $104 \quad(49)$ & $88 \quad(40)$ \\
\hline Black, n (\%) & $127 \quad(60)$ & $140 \quad(64)$ & $1,659 \quad(36)$ & $76 \quad(36)$ & $92 \quad(42)$ \\
\hline Hispanic, n (\%) & $36 \quad(17)$ & $31 \quad(14)$ & $92 \quad(2)$ & $2 \quad(1)$ & $1 \quad(0.5)$ \\
\hline \multicolumn{6}{|l|}{ Baseline utilizations } \\
\hline Mean AC hospitalizations & 0.12 & 0.11 & 0.16 & 0.12 & 0.09 \\
\hline Mean Psych hospitalizations & 0.10 & 0.11 & 0.11 & 0.11 & 0.09 \\
\hline \multicolumn{6}{|l|}{$\mathrm{OA}$ at index, $\mathrm{n}(\%)$} \\
\hline Aripiprazole & $34 \quad(16)$ & - & $784 \quad(17)$ & $28 \quad(13)$ & - \\
\hline Haloperidol & $15 \quad(7)$ & - & $507 \quad(11)$ & $15 \quad(7)$ & - \\
\hline Olanzapine & $36 \quad(17)$ & - & $645 \quad(14)$ & $23 \quad(11)$ & - \\
\hline Paliperidone & $45 \quad(21)$ & - & $277 \quad(6)$ & $17 \quad(8)$ & - \\
\hline Perphenazine & $19 \quad(9)$ & - & (1) & (1) & - \\
\hline Quetiapine & $28 \quad(13)$ & - & $1,290 \quad(27)$ & $61 \quad(29)$ & - \\
\hline Risperidone & $36 \quad(17)$ & - & $1,106 \quad(24)$ & $66 \quad(31)$ & - \\
\hline
\end{tabular}

a Projected to reflect the Medicaid sample using inverse probability weighting.

$A C=$ all-cause $; O A=$ oral antipsychotic $; P P=$ paliperidone palmitate; $P$ sych $=$ psychiatric . 